\title{
Research on the Multiple Attribute Decision Making Model of Intelligent Information Processing with Intuitionistic Fuzzy Information
}

\author{
Chenyang Chai*
}

School of Accountancy, Jiangxi University of Finance and Economics, Nanchang, Jiangxi, 330013, China

\begin{abstract}
In this paper, we shall investigate the multiple attribute decision making model of intelligent information processing with intuitionistic fuzzy information. Firstly, it introduces the concept of intuitionistic fuzzy sets and fuzzy number directly and sorting method, and the concept of intuitionistic fuzzy vector product. Secondly, puts forward the intuitionistic fuzzy set method of intuitionistic fuzzy transform, the Multiple Attribute Decision Making Model of Intelligent Information Processing with Intuitionistic Fuzzy Information. Finally, take soccer robot motion control as intelligent information processing example, sets up intelligent multiple attribute decision making model processing Intuitionistic Fuzzy Information with the fuzzy matrix, to study the feasibility of the application model in the real environment.
\end{abstract}

Keywords: Intuitionistic fuzzy sets, manual intelligent, the multiple attribute, decision-making model, fuzzy-set theory.

\section{INTRODUCTION}

With the needs of the development of social science and technology, it is necessary to use the computer intelligent processing information development become inevitable. For decades, computer scientists have been pursuing artificial intelligence - the use of computers to simulate human thinking, integrated neural networks [1], evolutionary computation and fuzzy system as a whole, which becomes an important development direction. Considering the reality of the uncertainty of multivariable conditions change, it is an important index of artificial intelligence information processing to form the correct decision-making mechanism rapidly. Compared with the traditional single instruction directional probable control, fuzzy control does not need set up precise mathematical model, which has strong robustness [2].

In recent years, as people of intuitionistic fuzzy sets theory research thorough, effective integration and intuitionistic fuzzy information processing is developing rapidly [3]. Due to the growing complexity of the social and economic environment, and uncertainty, People have different levels of hesitation in the process of understanding of things, which makes cognitive results show is sure, deny or somewhere in between [4]. When artificial intelligence processing with information under the condition of the complex, it faces the same problem to perception and processing decision-making information [5].

Fuzzy-set theory, which was created by Zadeh [6] of University of California in 1965, breaks classic set theory which is put forward by the cantor's major in the end of the 19th century [7]. Fuzzy set theory to express the important concept fuzziness of things: membership function [8]. This paper defines the concept of intuitionistic fuzzy Numbers and algorithms, uses the inner product between intuitionistic fuzzy vector express the change of intuitionistic fuzzy, according to the results more scientific decision-making, to intelligent processing with the multiple attribute decisionmaking model [9].

This paper introduces fuzzy set theory, constructs multiple attribute decision making model to meet the needs of the fuzzy control system of soccer robot design, explore whether the multiple attribute decision making model is scientific and feasible in the actual complex manipulation of the environment [10].

\section{PRELIMINARIES}

In the following, we introduce some basic concepts related to intuitionistic fuzzy sets [11].

Definition 1. Let $\mathrm{X}$ be a nonempty set, then make $\mathrm{A}$ as a intuitionistic fuzzy set.

$$
\mathrm{A}=\left\{\left\langle\mathrm{x}, \mu_{\mathrm{x}}, \mathrm{v}_{\mathrm{x}}\right\rangle \mid \mathrm{x} \in \mathrm{X}\right\}
$$

$\mu_{\mathrm{X}}$ is the membership of $\mathrm{X}, \mathrm{v}_{\mathrm{x}}$ is the Non-membership degree of X. Besides that,

$$
\pi_{x}=1-\mu_{x}-v_{x}, x \in X,
$$

$\pi_{x}$ is the hesitancy degree of $x$, which belongs to $X$.

Definition 2. Let $a$ is an intuitionistic fuzzy number.

$$
\alpha=\left(\mu_{a}, \mathbf{V}_{a}\right),
$$

Among this,

$\mu \quad \alpha \in[0,1], v a \in[0,1], \mu \quad \alpha+v a \leqslant 1$.

Definition 3. Let $a_{1}, a_{2}$ be intuitionistic fuzzy numbers [12].

2015 Bentham Open 


$$
\begin{aligned}
& a_{1}=\left(\mu_{\left.a_{1}, v_{a_{1}}\right),}\right. \\
& a_{2}=\left(\mu_{a_{2}, v_{a_{2}}}\right),
\end{aligned}
$$

Let $s\left(a_{1}\right)$ be the score value of $a_{1}$, let $s\left(a_{2}\right)$ is the score value of $\mathrm{a}_{2}$.

$$
\begin{aligned}
& s\left(a_{1}\right)=\mu_{1}-v_{1}, \\
& s\left(a_{2}\right)=\mu_{2}-v_{2},
\end{aligned}
$$

Let $h\left(a_{1}\right)$ be the accuracy of $\alpha_{1}$, let $h\left(a_{2}\right)$ is the accuracy of $\alpha_{2}$.

$$
\begin{aligned}
& \mathrm{h}\left(\mathrm{a}_{1}\right)=\mu_{1+} \mathrm{v}_{1}, \\
& \mathrm{~h}\left(\mathrm{a}_{2}\right)=\mu_{2+} \mathrm{v}_{2},
\end{aligned}
$$

so that,

$$
\begin{aligned}
& \text { if } s\left(a_{1}\right)<s\left(a_{1}\right) \text {, then } a_{1}<a_{2} \text {. } \\
& \text { if } s\left(a_{1}\right)=s\left(a_{1}\right), \\
& \text { (1)and } h\left(a_{1}\right)=h\left(a_{2}\right) \text {, then } a_{1}=a_{2}, \mu_{v 1}=\mu_{v 2} \text {, } \\
& \mathrm{V}_{a} 1=v_{a} \text {. } \\
& \text { (2) and } h\left(a_{1}\right)<h\left(a_{2}\right) \text {, then } a_{1}<a_{2}, \\
& \text { (3) and } h\left(a_{1}\right)>h\left(a_{2}\right) \text {, then } a_{1}>a_{2},
\end{aligned}
$$

Definition 4. Let matrix $R=\left(r_{i j}\right)_{n} \times m$, if

$$
r_{i j}(i=1,2, \cdots, n \text {, and } j=1,2, \cdots, m) \text {, }
$$

then $\mathrm{R}$ is intuitionistic fuzzy matrix.

$\mathrm{A}$ is an intuitionistic fuzzy set.

$$
A=\left\{a_{1}, a_{2}, \cdots, a_{n}\right\}
$$

Think about that any intuitionistic fuzzy subset $X$ can be expressed as intuitionistic fuzzy vector $\mathrm{X}$,

$$
\mathrm{X}=\left(\mathrm{x}_{1}, \mathrm{x}_{2}, \cdots, \mathrm{x}_{\mathrm{n}}\right)
$$

$\mathrm{x}_{\mathrm{i}}$ is an intuitionistic fuzzy number $(\mathrm{i}=1,2, \cdots, \mathrm{n})$. We can regard it as a line of $n$ column of the matrix [13].

If we make the concept which $\mathrm{X}$ actually express as a new domain of discourse: $B=\{f(x)\}$, then $X$ can be considered as an intuitionistic fuzzy relation from B to $A$ [14].

Definition 5. For any intuitionistic fuzzy vector, let $A=\left\{a_{1}\right.$, $\left.a_{2}, \cdots, a_{n}\right\}, B=\left\{b_{1}, b_{2}, \cdots, b_{n}\right\}$, so that

$$
\begin{aligned}
& A \odot \mathrm{B}=\mathrm{A} \circ \mathrm{B}^{\mathrm{T}}=\left(\mathrm{a}_{1}, \mathrm{a}_{2}, \cdots, \mathrm{a}_{\mathrm{n}}\right) \circ\left(\begin{array}{c}
b_{1} \\
b_{2} \\
\vdots \\
\vdots \\
b_{n}
\end{array}\right) \\
& =\left(\left(u_{a_{1}} \wedge u_{b_{1}}\right) \vee \cdots \vee\left(u_{a_{n}} \wedge u_{b_{n}}\right),\left(v_{a_{1}} \wedge v_{b_{1}}\right) \wedge \cdots \wedge\left(v_{a_{n}} \wedge v_{b_{n}}\right)\right)
\end{aligned}
$$

$\mathrm{A} \odot \mathrm{B}$ is the dot-product of $\mathrm{A}$ and $\mathrm{B}$ vectors, and the result is an intuitionistic fuzzy number [15].
Definition 6. A and B are intuitionistic fuzzy sets, let them be nonempty set, If there is a algorithm $\mathrm{f}$, which make any element a of A correspond to the only sure intuitionistic fuzzy subsets $\mathrm{Y}$ of $\mathrm{B}$, then $\mathrm{f}$ is an intuitionistic fuzzy mapping from A to B [16]. It also can be writed for this:

$$
f: A \rightarrow \operatorname{IF}(B), a \rightarrow f(a)=X
$$

Definition 7. A and B are intuitionistic fuzzy sets, let them be nonempty set, If there is a algorithm $\mathrm{T}$, which make any intuitionistic fuzzy subset $\mathrm{X}$ correspond to the only sure intuitionistic fuzzy subsets $\mathrm{Y}$, then $\mathrm{T}$ is an intuitionistic fuzzy transformation from A to B. It also can be writed for this:

$$
\mathrm{T}: \mathrm{IF}(\mathrm{A}) \rightarrow \mathrm{IF}(\mathrm{B}), \mathrm{x} \rightarrow \mathrm{T}(\mathrm{x})=\mathrm{Y}
$$

According to the above definition, it can consider the relationship between the intuitionistic fuzzy vector and intuitionistic fuzzy matrix [17].

Definition 8. For any intuitionistic fuzzy set $A, A=\{a 1, a 2$, $\ldots$, an $\}$, any intuitionistic fuzzy subset $\mathrm{X}$ of $\mathrm{A}$ can be expressed as intuitionistic fuzzy vector $X, X=\left(x_{1}, x_{2}, \ldots, x_{n}\right), x_{i}$ is an intuitionistic fuzzy number $(\mathrm{i}=1,2, \ldots, \mathrm{n})$. We can regard it as a line of $n$ column of the matrix, so that there is an intuitionistic fuzzy matrixR, $\mathrm{R}=\left(\mathrm{r}_{\mathrm{ij}}\right)_{\mathrm{n} \times \mathrm{m}}, \quad(\mathrm{i}=1,2, \ldots, \mathrm{n}, \quad$ and $\mathrm{j}=1,2, \ldots, \mathrm{m})[18]$. It also can be writed for this:

$$
\begin{aligned}
& X \circ R=\left(x_{1}, x_{2}, \cdots, x_{n}\right) \circ\left(\begin{array}{cccc}
r_{11} & r_{12} & \cdots & r_{1 m} \\
r_{21} & r_{22} & \cdots & r_{2 m} \\
\vdots & \vdots & \ddots & \vdots \\
r_{n 1} & r_{n 2} & \cdots & r_{n m}
\end{array}\right) \\
& =\left(\left(\left(u_{x_{1}} \wedge u_{r_{11}}\right) \vee \cdots \vee\left(u_{x_{n}} \wedge u_{r_{n 1}}\right),\right.\right. \\
& \left.\left(v_{x_{1}} \wedge v_{r_{11}}\right) \wedge \cdots \wedge\left(v_{x_{n}} \wedge v_{r_{n 1}}\right)\right), \cdots \cdots, \\
& \left(\left(u_{x_{1}} \wedge u_{r_{1 m}}\right) \vee \cdots \vee\left(u_{x_{n}} \wedge u_{r_{n m}}\right),\right. \\
& \left.\left.\left(v_{x_{1}} \wedge v_{r_{1 m}}\right) \wedge \cdots \wedge\left(v_{x_{n}} \wedge v_{r_{n m}}\right)\right)\right)
\end{aligned}
$$

$\mathrm{X} \odot \mathrm{R}$ is the dot-product of $\mathrm{X}$ and $\mathrm{R}$ vectors, and the result is an intuitionistic fuzzy set [19].

\section{MODEL THE MULTIPLE ATTRIBUTE DECISION MAKING MODEL OF INTUITIONISTIC FUZZY TRANSFORMATION}

Firstly, the following assumptions or notations are used to represent the intuitionistic fuzzy MADM problems with different weight information [20].

(1) The alternatives are known.

Let $\mathrm{A}$ be a discrete set of alternatives,

$$
A=\left\{A_{1}, A_{2}, \ldots, A_{m}\right\} \text {. }
$$

(2) The attributes are known.

Let $\mathrm{G}$ be a set of attributes,

$$
\mathrm{G}=\left\{\mathrm{G}_{1}, \mathrm{G}_{2}, \ldots, \mathrm{G}_{\mathrm{n}}\right\} .
$$

(3) The information about attribute weights is incompletely known. 
Let $\mathrm{w}$ be the weight vector of attributes,

$$
\mathrm{w}=\left(\mathrm{w}_{1}, \mathrm{w}_{2}, \ldots, \mathrm{w}_{3}\right) \in \mathrm{H} .
$$

$\left(\mathrm{w}_{\mathrm{j}} \geq 0, \mathrm{j}=1,2, \ldots, \mathrm{n}, \sum_{j=1}^{n} w_{j}=1\right)$

$\mathrm{H}$ is a set of the known weight information.

Suppose that $\mathrm{R}$ is the intuitionistic fuzzy decision matrix,

$$
R=\left(r_{i j}\right)_{m \times n}=\left(\eta_{i j}, v_{i j}\right)_{m \times n}
$$

$\left(\mu_{i j} \in[0,1], v_{i j} \in[0,1], \mu_{i j}+v_{i j} \leqslant 1, i=1,2, \ldots, m\right.$,and $j=1,2, \ldots$ ,n)

$\mu_{\text {ij }}$ indicates the degree of the alternative, $A_{i}$ satisfies the attribute $G_{j}$ given by the decision maker, $v_{i j}$ indicates the degree of the alternative. $A_{i}$ doesn't satisfy the attribute $G_{j}$ given by the decision maker [21].

Secondly, analysis of the principle of intuitionistic fuzzy multiple attribute decision making, we can use the principle of intuitionistic fuzzy transformation to integrating information for intelligent decision.

Thirdly, we can develop a practical model for solving the MADM problems based on the above methods, whose attribute value and weight value are in the form of an intuitionistic fuzzy information [22], which involve the following steps:

Step 1. Let the set of alternatives be selected,

$$
A=\left\{A_{1}, A_{2}, \cdots, A_{n}\right\},
$$

with the attribute set,

$$
\mathrm{X}=\left(\mathrm{x}_{1}, \mathrm{x}_{2}, \cdots, \mathrm{x}_{\mathrm{m}}\right) .
$$

Step 2. Let the intuitionistic fuzzy weighted vector is given,

$$
\begin{aligned}
& \mathrm{W}=\left(\mathrm{w}_{1}, \mathrm{w}_{2}, \cdots, \mathrm{w}_{\mathrm{m}}\right), \\
& \mathrm{w}_{\mathrm{i}} \text { is intuitionistic fuzzy number. }
\end{aligned}
$$

Step 3. Let $u_{i j} \in[0,1], v_{i j} \in[0,1]$ denote respectively $A_{j} \in A$ meet the extent of the attribute $x_{i} \in X$.

And $0 \leqslant u_{i j}+v_{i j} \leqslant 1$, which means the evaluation of $A_{j}$ about attribute $x_{i}$ can be expressed as $F_{i j}=\left(u_{i j}, v_{i j}\right)$ with intuitionistic fuzzy numbers.

$M$ attributes of attribute values in opration $A_{j}$ can be expressed as :

$$
\begin{aligned}
& A_{j}=\left(F_{1 j}, F_{2 j}, \cdots, F_{n j}\right) \\
& =\left(\left(u_{1 j}, v_{1 j}\right),\left(u_{2 j}, v_{2 j}\right), \cdots,\left(u_{m j}, v_{n j},\right)\right)
\end{aligned}
$$

So that the intuitionistic fuzzy comprehensive decision evaluation set can be expressed as :

$$
F=\left(f_{i j}\right)_{m \times n}
$$

Step 4. From naturalizing intuitionistic fuzzy matrix $\mathrm{F}=\left(\mathrm{f}_{\mathrm{ij}}\right)_{\mathrm{m} \times \mathrm{n}}$, we can get new intuitionistic fuzzy matrix:

$$
\begin{aligned}
& R=\left(r_{i j}\right)_{m \times n} \\
& r_{i j}=\left(u_{r_{i j}}, v_{r_{i j}}\right)=\left(\frac{u_{f}}{\sum_{i=1}^{m} u_{f}}, \frac{v_{f}}{\sum_{i=1}^{m} v_{f}}\right)
\end{aligned}
$$

Step 5. Let membership and non-membership degree of intuitionistic fuzzy weight vector $\mathrm{W}$ be naturalized respectively, is to get a new intuitionistic fuzzy weight vector Q:

$$
\begin{aligned}
& Q=\left(q_{i}\right)_{1 \times m} \\
& q_{i}=\left(u_{i}, v_{i}\right)=\left(\frac{u_{w_{i}}}{\sum_{i=1}^{m} u_{w_{i}}}, \frac{v_{w_{i}}}{\sum_{i=1}^{m} v_{w_{i}}}\right)
\end{aligned}
$$

Step 6. Using the new intuitionistic fuzzy decision matrix $\mathrm{R}(15)$, transform intuitionistic fuzzy vector Q (17) by definition 8 , we can get an intuitionistic fuzzy set $\mathrm{Z}$.

Step 7. Let these elements in the collection of $\mathrm{Z}$ can be sorted by the Definition 3, we can get decision result [23].

\section{EXAMPLE OF APPLIED STUDY}

Robot soccer game is a typical in the field of intelligent robot multi-agent systems, which is the current simulation, artificial intelligence and one of the hot research topic in the field of robot [24].

Soccer robot integrates intelligent control system, environmental perception system, wireless communication system and decision-making system as a whole. Take soccer robot with four wheel drive for an example, whose motion control diagram is as follows Fig. (1):

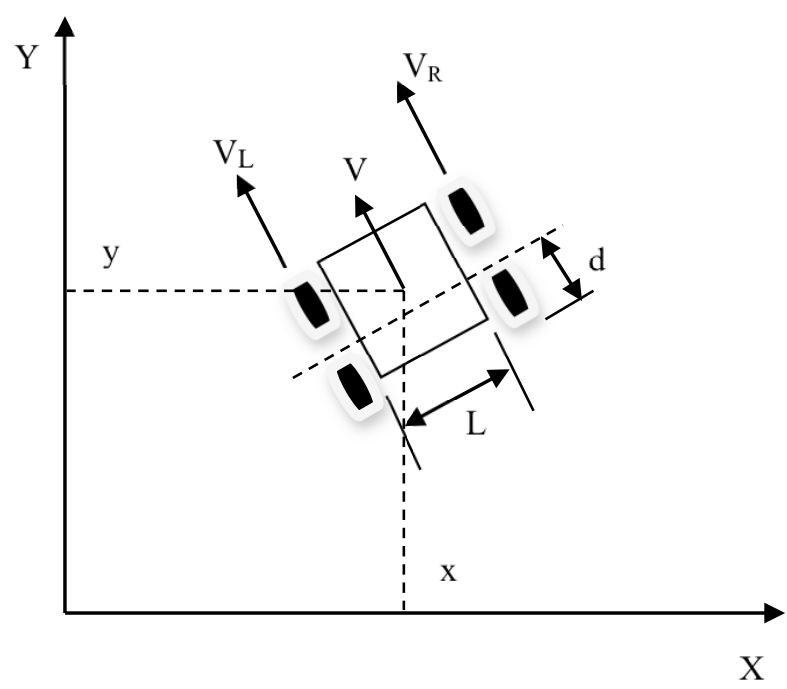

Fig. (1). Motion control diagram.

For soccer robot which is created by the simulation and visualization technology, motion control is its most basic function, which realizes the point-to-point and arbitrary angle motion accurately and quickly [25]. Because of the lag- 
ging behind of image acquisition and image recognition accuracy at short notice, robots must be fast and accurate tracking of football of autonomous navigation, path planning and decision making. Therefore, the effective control of the robot movement is the key factors that decide the final game Fig. (2).

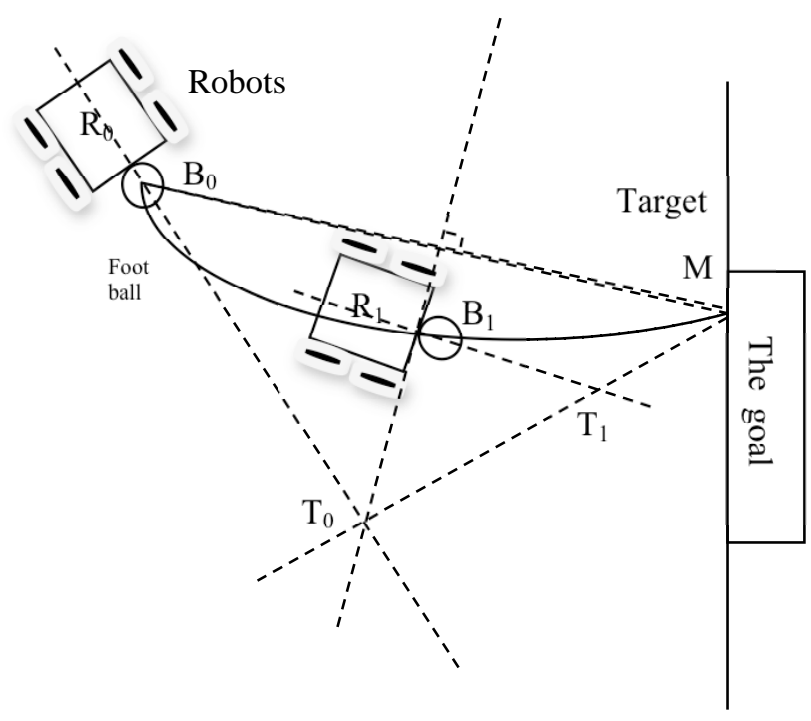

Fig. (2). Movement locus diagram.

At present, combining fuzzy control and traditional PID control of the control method is the mainstream of the motion control of soccer robot system [26]. Its working principle is to improve the quickness of perception information processing with introducing the fuzzy control, achieve the accuracy of the control by PID control.

In the game, roberts have four control modes,such as hold the ball, catch the ball, stop the ball and kick the ball [27], which can be expressed as $A_{j}(j=1,2,3,4)$. Factors that affect action decision include energy consumption, responsive time, tactical formation and collision forecast, which can be expressed as $x_{i}(i=1,2,3,4)$. The intuitionistic fuzzy weighted vector of attribute-evaluation model is $\mathrm{W}$,

$$
\mathrm{W}=((0.30 .0 .60),(0.20,0.75),(0.35,0.55),(0.15,0.65)) .
$$

The characteristic information of every control mode under the evaluation factors is expressed with intuitionistic fuzzy number. So the evaluation result is an intuitionistic fuzzy matrix [28].

$$
\left.\begin{array}{ccccc} 
& A_{1} & A_{2} & A_{3} & A_{4} \\
x_{1} & ((0.5,0.4) & (0.7,0.3) & (0.6,0.4) & (0.8,0.1) \\
x_{2} & (0.6,0.3) & (0.7,0.2) & (0.3,0.5) & (0.6,0.3) \\
x_{3} & (0.3,0.6) & (0.3,0.5) & (0.5,0.3) & (0.3,0.4) \\
x_{4} & (0.2,0.8) & (0.6,0.3) & (0.2,0.6) & (0.4,0.6)
\end{array}\right)
$$

Let the matrix $\mathrm{R}$ be naturalized, we can get a new in tuitionistic fuzzy decision matrix.
$\vec{R}=$
$\left(\begin{array}{llll}(0.9123,0.3333) & (0.2692,0.2500) & (0.2308,0.3333) & (0.3077,0.0833) \\ (0.2727,0.2308) & (0.3182,0.1538) & (0.1364,0.3846) & (0.2727,0.2308) \\ (0.1765,0.4000) & (0.3592,0.1333) & (0.2941,0.2000) & (0.1765,0.2677) \\ (0.1667,0.3200) & (0.3333,0.2000) & (0.1667,0.2400) & (0.3333,0.2400)\end{array}\right)$

Let membership and non-membership degree of intuitionistic fuzzy weight vector $\mathrm{W}$ be naturalized respectively [29], we can get $\mathrm{Q}$ :

$\mathrm{Q}=((0.30,0.24),(0.20,0.30),(0.35,0.22),(0.15,0.24))$

Using the new intuitionistic fuzzy matrix $\mathrm{R}$, transform intuitionistic fuzzy weight vector Q :

$$
\begin{aligned}
& Z=Q \circ R \\
& =((0.30,0.24),(0.20,0.30),(0.35,0.22),(0.15,0.24)) \circ \\
& \left(\begin{array}{llll}
(0.9123,0.3333) & (0.2692,0.2500) & (0.2308,0.3333) & (0.3077,0.0833) \\
(0.2727,0.2308) & (0.3182,0.1538) & (0.1364,0.3846) & (0.2727,0.2308) \\
(0.1765,0.4000) & (0.3592,0.1333) & (0.2941,0.2000) & (0.1765,0.2677) \\
(0.1667,0.3200) & (0.3333,0.2000) & (0.1667,0.2400) & (0.3333,0.2400)
\end{array}\right) \\
& =((0.2,0.3),(0.35,0.22),(0.2941,0.22),(0.3,0.24))
\end{aligned}
$$

We can sort intuitionistic fuzzy Numbers in the collection of $\mathrm{Z}$ by the Definition 4:

$$
\begin{aligned}
& s(0.2000,0.3000)=-0.1 \\
& s(0.3500,0.2200)=0.13 \\
& s(0.2941,0.2200)=0.0741 \\
& s(0.3000 .0 .2400)=0.06
\end{aligned}
$$

Obviously, $\mathrm{A}_{2}>\mathrm{A}_{3}>\mathrm{A}_{4}>\mathrm{A}_{1}$

so that the second control mode is the right choice for playing.

\section{CONCLUSION}

In this paper, we study on the multiple attribute decision making model based on intuitionistic fuzzy transformation, find a way to solve multiple attribute decision making problems when its weight value is the number of intuitionistic fuzzy [30]. It doesn't complex operation, which can improve the rapidness and veracity of computer intelligent processing sensory information with fuzzy control technology effectively in the real application especially, which have extensive application and broad prospects, demonstrate its practicality and effectiveness.

\section{CONFLICT OF INTEREST}

The authors confirm that this article content has no conflicts of interest.

\section{ACKNOWLEDGEMENTS}

This work is supported by the Project of Youth Science Fund (GJJ10121) of The Education Department of Jiangxi Province, China. 


\section{REFERENCES}

[1] K. Atanassov, "Intuitionistic fuzzy sets," Fuzzy Sets and Systems, vol. 20, pp. 87-96, 1986.

[2] K. Atanassov, "More on intuitionistic fuzzy sets," Fuzzy Sets and Systems, vol. 33, pp.37-46, 1989.

[3] L. A. Zadeh, "Fuzzy sets," Information and Control, vol. 8, pp. 338-356, 1965.

[4] W. L. Gau, and D. J. Buehrer, "Vague sets," IEEE Transactions on Systems, Man and Cybernetics, vol. 23, no. 2, pp. 610-614, 1993.

[5] H. Bustine, and P. Burillo, "Vague sets are intuitionistic fuzzy sets," Fuzzy Sets and Systems, vol. 79, pp. 403-405, 1996.

[6] S.M. Chen, and J.M. Tan, "Handling multicriteria fuzzy decisionmaking problems based on vague set theory," Fuzzy Sets Systems, vol. 67, pp. 163-172, 1994.

[7] D. H. Hong, and C.H. Choi, "Multicriteria fuzzy decision-making problems based on vague set theory," Fuzzy Sets Systems, vol. 114, pp. 103-113, 2000.

[8] D.F. Li, "Multiattribute decision making models and methods using intuitionistic fuzzy sets," Journal of Computer and System Sciences, vol. 70, pp. 73-85, 2005.

[9] L. Lin, X.H. Yuan, and Z.Q. Xia, "Multicriteria fuzzy decisionmaking methods based on intuitionistic fuzzy sets," Journal of Computer and System Sciences, vol. 73, pp. 84-88, 2007.

[10] G.W. Wei, "Maximizing deviation method for multiple attribute decision making in intuitionistic fuzzy setting," Knowledge-Based Systems, vol. 21, no.8, pp. 833-836, 2008.

[11] G. W. Wei, "GRA method for multiple attribute decision making with incomplete weight information in intuitionistic fuzzy setting," Knowledge-Based Systems, vol. 23, no. 3, pp. 243-247, 2010.

[12] G. W. Wei, "Some induced geometric aggregation operators with intuitionistic fuzzy information and their application to group decision making,' Applied Soft Computing, vol. 10, no. 2, pp. 423-431, 2010.

[13] D.F. Li, Y. C. Wang, S. Liu, and F. Shan, "Fractional programming methodology for multi-attribute group decision making using IFS," Applied Soft Computing Journal, vol. 9, no. 1, pp. 219-225, 2009.

[14] J. Ye, "Improved method of multicriteria fuzzy decision-making based on vague sets," Computer-Aided Design, vol. 39, pp. 164$169,2007$.

[15] G. W. Wei, X.F. Zhao, H.J. Wang and R. Lin, "GRA model for selecting an ERP system in trapezoidal intuitionistic fuzzy setting," Information: An International Journal, vol. 13, no. 4, pp. 11431148,2010

[16] T. Gerstenkorn, and J. Manko, "Correlation of intuitionistic fuzzy sets," Fuzzy Sets and Systems, vol. 44, pp. 39-43, 1991.
[17] Z. S. Xu, "Intuitionistic fuzzy aggregation operators," IEEE Transations on Fuzzy Systems, vol. 15, no. 6, pp.1179-1187, 2007.

[18] H.J. Zimmermann, and P. Zysco, "Latent connectives in human decision making," Fuzzy Sets and Systems, vol. 4, pp. 37-51, 1980.

[19] F. Herrera and E. Herrera-Viedma, "Linguistic decision analysis: steps for solving decision problems under linguistic information," Fuzzy Sets and Systems, vol. 115, pp. 67-82, 2000.

[20] G. W. Wei, "Some geometric aggregation functions and their application to dynamic multiple attribute decision making in intuitionistic fuzzy setting, International Journal of Uncertainty," Fuzziness and Knowledge- Based Systems, vol. 17, no. 2, pp. 179-196, 2009.

[21] Z. S. Xu, "Models for multiple attribute decision-making with intuitionistic fuzzy information, International Journal of Uncertainty": Fuzziness and Knowledge-Based Systems, vol. 15, no. 3, pp. 285-297, 2007.

[22] Z. S. Xu, "A method based on distance measure for interval-valued intuitionistic fuzzy group decision making," Information Sciences, vol. 180, no. 1, pp. 181-190, 2010.

[23] G. W. Wei, R. Lin, X.F. Zhao and H.J. Wang, "TOPSIS-based linear-programming methodology for multiple attribute decision making with incomplete weight information in intuitionistic fuzzy setting," Information: An International Journal, vol. 13, no. 5, 2010.

[24] Z. S. Xu, "Multi-person multi-attribute decision making models under intuitionistic fuzzy environment," Fuzzy Optimization and Decision Making, vol. 6, no. 3, 221-236, 2007.

[25] Z. S. Xu and R. R. Yager, "Some geometric aggregation operators based on intuitionistic fuzzy sets," International Journal of General System, vol. 35, pp. 417-433, 2006.

[26] L. Lin, X. H. Yuan and Z.Q. Xia, "Multicriteria fuzzy decisionmaking methods based on intuitionistic fuzzy sets," Journal of Computer and System Sciences, vol. 73, pp. 84-88, 2007.

[27] G. W. Wei, H.J. Wang, and R. Lin, "Application of correlation coefficient to interval-valued intuitionistic fuzzy multiple attribute decision making with incomplete weight information," Knowledge and Information Systems, vol. 26, no. 2, pp. 337-349, 2011.

[28] D.F. Li, "Extension of the LINMAP for multiattribute decision making under Atanassov's intuitionistic fuzzy environment," Fuzzy Optimization and Decision Making, vol. 7, no. 1, pp. 17-34, 2008.

[29] D. F. Li, "Some measures of dissimilarity in intuitionistic fuzzy structures," Journal of Computer and systems Sciences, vol. 68, no. 1, pp. 115-122, 2004.

[30] H.W. Liu, and G.J. Wang, "Multi-criteria decision-making methods based on intuitionistic fuzzy sets," European Journal of Operational Research, vol. 179, no. 1, pp. 220-233, 2007.

Received:

Revised:

Accepted:

(C) Chenyang Chai; Licensee Bentham Open.

This is an open access article licensed under the terms of the (https://creativecommons.org/licenses/by/4.0/legalcode), which permits unrestricted, non-commercial use, distribution and reproduction in any medium, provided the work is properly cited. 